\title{
Experimentally Fused Larvae of Echinoderms, with Special Reference to their Skeletons.
}

Part 2. Arbacia punctulata.

By

\author{
A. J. Goldfarb, \\ College of the City of New York.
}

With Plates XIV-XX.

Eingegangen am 10. Juli 1914.

Contents,

Introduction.

Method of fusing the egrs.

Normal larvae . . . . . . . . . . . . . . . . . . . . . . . . . . . 581

Fused larvae . . . . . . . . . . . . . . . . . . . . . . . . . . . . 584

Fused larvae with fused skeletons . . . . . . . . . . . . . . . 587

a) Equal larvae, both normal . . . . . . . . . . . . . . . 587

b) Unequal larvae . . . . . . . . . . . . . . . . 588

1) One normal and one incomplete larva. . . . . . . . . . . . 588

2) One normal and one extremely atypic larva . . . . . . . . . o90

c) Both larvae modified . . . . . . . . . . . . . . . . . . . . 593

Discussion . . . . . . . . . . . . . . . . . . . 595

Summary . . . . . . . . . . . . . . . . . . 601

Zusammenfassung . . . . . . . . . . . . . . . . . 602

Bibliography ................... . 604

List of abbreviations. . . . . . . . . . . . . . . . . . 604

\section{Introduction.}

In this paper it is proposed to describe in detail some of the larvae of the sea urchin Arbacia punctulata that were experimentally fused together. Special emphasis will be given to the consideration of the skeletons of these larvae, for they afford a clear and a definite basis for an understanding of certain embryonic regulations that obtain in fused larvae only.

Fused eggs and fused embryos derived from whole eggs have been observed by a number of investigators, Morgan in 1895, Zur 
Strassen in 1898, Patrenson 1913 and by many others. These observations suggested the idea that separately fertilized eggs might be experimentally fused together; and in 1910 DrIEsch finally succeed in so doing, and in 1913 Goldfarb and Bierens de HaAN independently succeeded in fusing the eggs together in a number of different species of sea aurchins. These experimentors showed 1) as many as 40 eggs could be agglutinated to one another (GoLDFARB), 2) an agglutination of more than two eggs rarely developed beyond an early stage (Loeb, Morgan, Goldfari, de HaAN), 3) some of the agglutinated eggs were fused together either during the egg stage (DE HAAN) or during subsequent development (DRIEsCH, GOLDFARB), 4) the larvae resulting from such agglutinated eggs varied with the extent of the agglntinated surfaces and the time at which fusion occurred (GOLDFARB), 5) the resulting larvae might be grouped into the following categories (Driesch, Goldvarib):

a) two larvae attached to one another with no common body cavity, not a true fusion,

b) two larvae with a continuons body cavity, a true fusion,

c) two larvae with guts as well as body cavity fused,

d) two larvae fused together but unequally developed,

e) one giant fused larva.

In 1914 the writer made the first intensive study of the skeletons in these various types of experimentally fused larvae of the sea urchin Toxopneustes variegatus. In this paper it is proposed to describe in detail some of the experimentally fused larvae of the Arbacia punctulata, and to compare them with the fused larvae of Toxopneustes.

\section{Method of Fusing the Eggs.}

The method which was first used so successfully with Toxopneustes (4) was tried with Arbacia eggs and gave rise to an extraordinarily large number of agglutinations and fusions. The method consisted in placing the eggs shortly after fertilization into an isotonic or hypotonic $\mathrm{NaCl}$ solution in sea water. For example

100 ce. of sea water +0 ce $\mathrm{M} .5 \mathrm{NaCl}$

75 to 50 cc. sea water +25 to 50 cc. $\mathrm{M} .5 \mathrm{NaCl}$

45 to 20 cc. sea water +55 to 80 cc. M $.5 \mathrm{NaCl}$

15 to 0 ce. sea water +85 to 100 cc. M. $.5 \mathrm{NaCl}$
Controls

Few fusions

Many fusions

No fusions, atypic or no development. 
The eggs were left in these solutions 8 to 10 hours, and then transferred after several changes, to sea water, in which all further development took place. Table 1 gives further details concerning the concentration of the sodium chloride, the time and date of exposure, etc. This table and the results of other experiments make it evident that at least three factors condition the fusion of the eggs, 1) the sodium chloride must be isotonic or hypotonic, 2) the optimum solution varies from 55 to 80 percent of the sodium chloride in sea water, 3) eggs must be exposed to these solutions for 7 to 10 hours.

It is evident from Tables 1 and 2 that even when these three factors are present that the eggs did not fuse in a large number of the experiments, and that other factors must be involved. For example in series 1, 2 and 3 of Table 1, derived from the same batch of eggs, only series 2 gave positive results. Series 4,5 and 6 from another batch of eggs treated in the same manner as the three preceeding series, gave no fusions. The concentration of the $\mathrm{NaCl}$ was changed in series $11,12,13,14,15,21,22,28,29$, and 30 without any positive results. Series 23 to 27 however gave rise to fusions in the hypotonic solutions.

DE HAAN expressed the belief that a seasonal change in the germ cells or in the environment might favor the fusion at one time and not at another. At first I was inclined to accept this view but further data gave no support to this conclusion. In Arbacia Table 1, fusions occurred in cultures fertilized July 12, and no more fusions were obtained until August 7th although experiments were made almost daily. Similarly Toxopneustes eggs were first fused on July 3rd (Table 2), fewer were obtained on July 5th; still less on July 6, 7 and 8th. After July 10 there were no fusions though the method, the temperature and the other conditions were the same. On July $22 \mathrm{nd}$, however fusions occurred but in one series only, all others gave negative results. There is unquestionably an undetermined factor, which is probably not a seasonal change nor a ehange in the ripeness or overripeness of the germ cells as was determined by suitable experiments. What this factor is, I have not yet determined.

\section{Normal Larvae.}

I have elsewhere (3) described in detail the early stages in the development of agglutinated and fused eggs of Arbacia punctulata. The present paper will therefore be limited to a consideration of the 
Table 1. Arbacia punctulata.

Gives the variable conditions in each experiment and states whether fusions were or were not obtained in each experiment.

\begin{tabular}{|c|c|c|c|c|c|c|}
\hline $\begin{array}{c}\text { Series } \\
\text { No. }\end{array}$ & Concentration & Time & & Date & \multicolumn{2}{|c|}{ Results } \\
\hline 1 & $.5 \mathrm{M} . \mathrm{NaCl}$ & 6 & July 12 & & No fusions & \\
\hline 2 & $. \overline{0}-\quad-$ & 10 & -12 & 1 batch of eggs & & Many fusions \\
\hline 3 & $\tilde{0}-\quad-$ & 8 & -121 & & No fusions & \\
\hline 4 & .5 M. $\mathrm{NaCl}$ & 11 & July 30 & & & \\
\hline 5 & $.5-\quad-$ & 10 & - 30 & 1 batch of eggs & No fusions & \\
\hline 6 & $\dot{\delta}-\quad-$ & $91 / 2$ & -301 & & & \\
\hline 7 & $.5 \mathrm{M} . \mathrm{NaCl}$ & 9 & July 31 & & & \\
\hline 8 & $.5-\quad-$ & 10 & -31 & 1 batch of eggs & No fusions & \\
\hline 9 & $.5-$ & 11 & $-31)$ & & & \\
\hline 11 & Mol. $\mathrm{NaCl}$ & 4 & Aug. 2 & & & \\
\hline 12 & $.8 \mathrm{ML} \quad-$ & $6-7$ & -2 & & & \\
\hline 13 & $.6-$ & 8 & -2 & 1 batch of eggs & No fasions & \\
\hline 14 & .4 & $6-8$ & 2 & 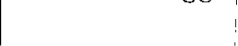 & ! & \\
\hline $1 \tilde{0}$ & $.2-\quad-$ & $3-4$ & $-2)$ & & & \\
\hline 17 &.$\tilde{\mathrm{M}} \cdot \mathrm{NaCl}$ & 8 & Aug. 5 & & & \\
\hline 18 & $.5-\quad-$ & 10 & $-5\}$ & 1 batch of eggs & No fusions & \\
\hline 19 & $. \check{a}-\quad-$ & $111 / 2$ & -51 & & & \\
\hline 20 & $. \check{s} \mathrm{M} . \mathrm{NaCl}$ & 10 & Aug. $\tilde{5}$ & & & \\
\hline 21 & $.4-$ & 8 & 5 & 1 batch of eggs & No fusions & \\
\hline 22 & $.4-\quad-$ & 10 & 51 & & & \\
\hline 23 & $.4 \mathrm{M} . \mathrm{NaCl}$ & $71 / 2$ & Aug. 7 ) & & & Some fusions \\
\hline 24 & $.4-$ & $91 / 2$ & -7 & & & Some fusions \\
\hline 25 & $.5-$ & $91 / 2$ & 7 & 1 batch of egges & No fusions & \\
\hline 26 & $. \check{s}-$ & $111 / 2$ & 7 & & No fasions & \\
\hline 27 & .3 & $71 / 2$ & 7 & & & Some fusions \\
\hline 28 & $.3-\quad-$ & $81 / 2$ & 7 & & No fusions & \\
\hline 29 & .4 M. $\mathrm{NaCl}$ & 6 & Aug. 12 & & & \\
\hline 30 & $.3-\quad-$ & $5-7$ & $-12\}$ & 1 batch of eggs & No fusions & \\
\hline 31 & $. \tilde{\delta}-$ & 9 & -12 & & & \\
\hline
\end{tabular}

fnlly developed larvae. Ordinarily the pluteus stage is reached in about 48 hours. During the succeeding 3 or 4 days no other changes occur except a small reduction in the size of the larva, as shown by Tennenr ' 10 . This fixity of form obtains much longer in Arbacia where no material change occurs during the 14 days in which the 
Experimentally Fused Larvac of Echinoderms etc. 2.

Table 2. Toxopneustes variegatus.

Gives the same data as Table 1 for the eggs of Toxopneustes.

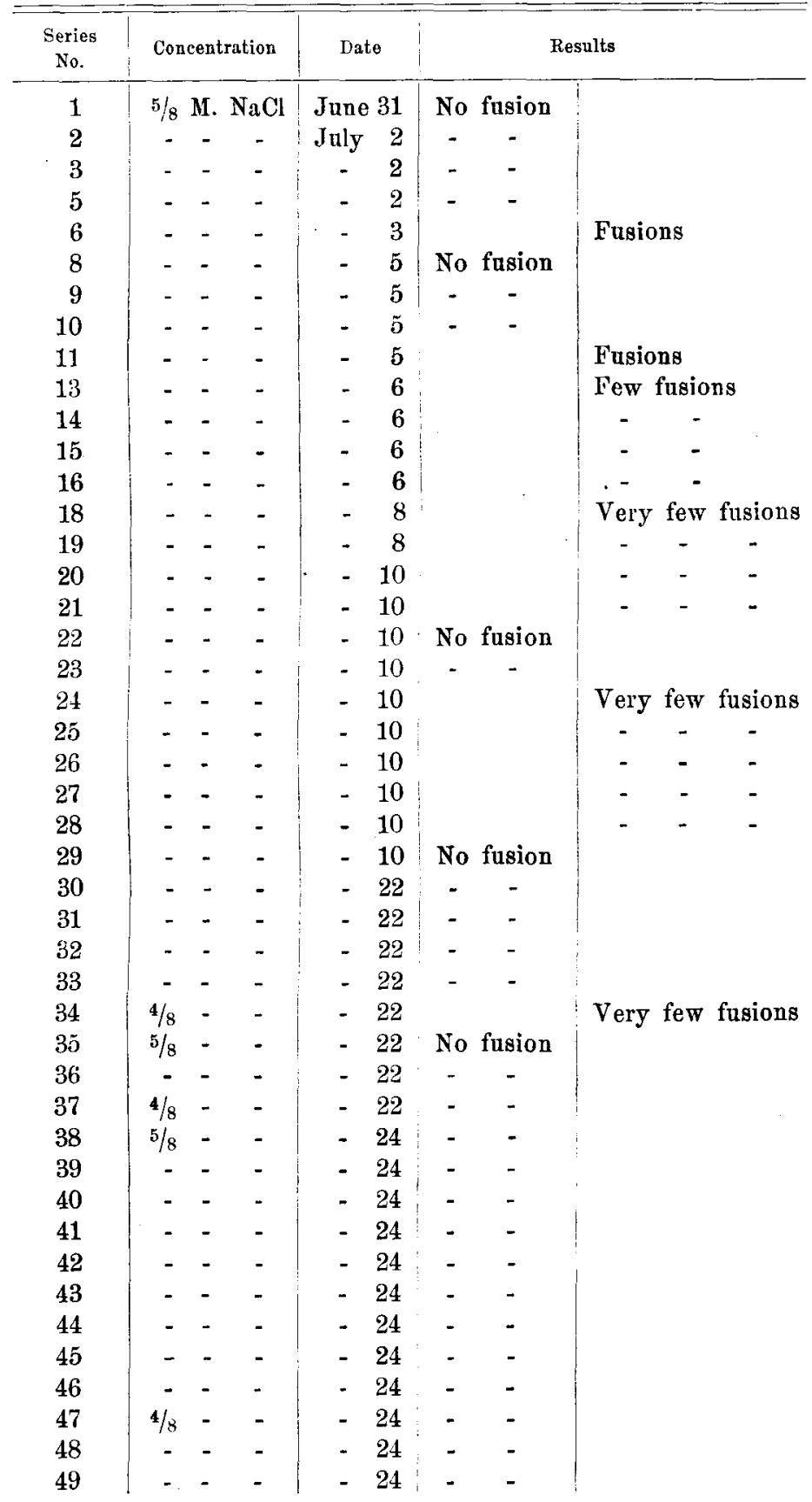


larva were under observation, except the small reduction in size already referred to, and probably due to the absence of proper food.

The skeleton is bilaterally symmetrical composed of 12 easily recognizable parts. These parts possess certain definite characteristics which readily distinguish them from one another even when the parts are shifted abbreviated or even malformed. From each of the two skeleton forming centers $S . C$., and on the anal side of the larva there extends a long, wide fenestrated rod known as the anal arm rod A.A.R. On the same side and extending in the opposite direction there is a stout non-fenestrated rod the body rod B.R., which ends aborally in a tetrahedral mass known as the aboral branches $\dot{A}$. $B r$. From each skeleton center two thin almost straight rods connect the two anal arm rods, known as the anal connectives $A . C$., and at right angles to these are the two dorso-ventral connectives $D . V . C$, somewhat thicker at the bases and bent orally and dorsally into two oral arm rods O.A.R.

These structures are shown in Fig. 1, oral view, Fig. 2, anal view, and Fig. 3, lateral view. The spines and fenestrations are not always indicated in the drawings. These and all the other drawings were made to the same scale with an ocular 4, objective $1 / 4$ tube length 160 giving a magnification of 490 subsequently reduced to $3 / 4$.

It is known largely through the observations of Tennent that certain variations from the norm occur in control cultures, for example:

1) one or more parts of the larval skeleton may be abbreviated,

2) one entire arm rod may be missing,

3) the entire skeleton may be smaller than the norm,

4) one or more parts of the skeleton may be elongated,

5) a supernumerary rod may be present,

6) one or more parts of the skeleton may be otherwise deformed.

In nearly every culture a very small proportion of the larvae showed these types of variants. They are here cited in order to distinguish them from the variations that are found only in fused larvae.

\section{Fused Larvae.}

By the term "fused larva is meant that two larvae have a common body cavity and a continuous body wall, with or without the fusion of other parts of the two organisms. I have found no 
clear example of the fusion of more than two larvae derived from whole eggs, though the fusion of three or more half eggs or quarter eggs may be produced in considerable numbers (3). Agglutinated larvae will likewise not be referred to, because in such instances, each larva is normal and gives no evidence of the interesting modifications that obtain in nearly all fused larvae.

Fig. 4 is an example of the fusion of two almost equal larvae fused aborally. On close examination it is seen that the right larva is perfect in every detail, the left however is not quite normal. In the first place the two anal arm rods and the two body rods are unusually close together. But a much more striking change is seen in the union of the exceedingly thin oral arm rods which are joined by a single stout dorso-ventral connective to the anal connectives. Associated with this thinning of the oral rods, not well shown in the figure, and the loss of one dorso-ventral connective there is a thickening of the single dorso-ventral connective and several supernumerary bars at $s^{1}$ and $s^{2}$. In other respects the two skeletons and the two larvae are typical and though overlapping at their aboral ends are not fused together ${ }^{1} \mathrm{j}$. It will be of interest to note that the lower larva has no gut. The upper one has a complete gut of which the middle part is considerably enlarged and extends into the body of the other larva. The single hind gut is shifted to one side and is normal in size.

Fig. 5 is another example of the fusion of two nearly equal and perfect larvae. The right one has all the skeletal parts fully and normally developed. The right is not quite perfect, for the two oral arm rods of which only one is shown in the figure are considerably abbreviated. The rest of the skeleton and larva are normal. Though the skeletal parts overlap there is no evidence of the fusion of the two skeletons.

Fig. 6 is an outline drawing of a fused pair in which the two larvae are unequally developed. The right one very much foreshortened, is quite perfect; the left one however is incomplete for the

1. In an effort to make more clear the limits of each larva the parts of one are drawn in full continuous lines, the parts of the other in dotted lines. In many instances the boundary can not be determined with exactness and the suggested boundaries are only approximations. This approximation of the boundary in no way interferes with the general conclusions. It may be of further assistance to note that the parts of the dominant larva are referred to in capital letters and the parts of the suppressed larva in small letters. 
entire oral half of the skeleton including both oral arms and both connectives are missing. Associated with this reaction or suppression of half of the larva there is a compensatory growth within the defective larva seen most clearly at $s^{1}, s^{2}$ and $s^{3}$ etc.

Fig. 7 also represents a union of a complete and an incomplete larva. The incomplete member contains even less than one half of the skeleton. There are two somewhat modified aboral branches two body rods which unite into a single anal arm rod. This figure differs from the preceding one not merely in the greater reduction of the suppressed larva, but in the fact, not nncommon among fused larvae, that the normal larva is also modified. For example, the two oral arm rods are united at their bases, and the aboral branches particularly the left one is atypic. It will be noted that the complete larva contains a normal gut though shunted somewhat to one side: the incomplete larva has also a gut but very atypic, consisting of but one of the characteristic parts of the normal gut. In this fused pair of larvae the gut and the skeleton are incomplete in only one of the larvae.

In other fused larvae, the abnormality though limited to one member, is due not so much to the suppression of the skeleton nor to compensatory growths but rather to the irregular formation of the characteristic struetures. For example, in Fig. 8, the upper larva is perfect, the lower one is dwarfed incomplete and irregular. It consists merely of two body rods two other rods which are probably the two anal arm rods, one oral arm rod, and an incomplete and irregular gut. The marked irregularity of the parts stands out in sharp contrast to the perfect and normal development of the upper larva.

The irregularity is carried further in Fig. 9. Externally and upon superficial examination there appears to be a single larva to which is attached a smal supernumerary arm at the aboral end. This supernumerary arm however is really an irregular and incomplete larva, containing two dwarfed and fused, yet characteristic anal arm rods connected to two characteristic body rods, and two normal aboral branches. There is no trace of the dorsal half of the body or of the gut.

In Fig. 10, the suppressed larva is even more irregular and its size still further reduced. Its skeleton consists of a large fenestrated and irregular sheet of calcareous material whose parts can not be homologized with the structures in the control larva. The larva is 
obviously less than one half of the norm. In spite of the extremely atypic development of the skeleton the gat is almost perfect, showing that the factors that make for irregular development in one organ, do not necessarily effect the other organ.

\section{Fused Larvae with Fused Skeletons.}

The examples so far cited, though they vary considerably in detail, agree in this, that the parts of the skeleton though they may overlap or be in contact, did not fuse together. In this respect these larvae are identical with those of Toxopneustes fused larvae described elsewhere.

The great majority of the fusions of Arbacia differed from these in the fact that the parts of the two skeletons did fuse together, with results shown in the following examples.

\section{a. Equal Larvae, Both Normal.}

Figs. 11 and 12 are representative of a small group of fusions in which both larvae are essentially perfect and equal in size, and in which the skeletons are fused together. They differ in no important respect from similar larvae whose skeletons have not fused together as in Figs. 4 and 5.

In Fig. 11, the lower larva is foreshortened in the drawing, making it appear smaller than it really is. In the upper larva as well as in the lower one, practically all the skeletal parts are well formed and full size. In the aboral regions of the two larvae a few atypic parts may be found, first, the aboral branches of both are missing, second, the left body rod of the upper larva has fused with the right body rod of the lower larva and the resulting fused rod is irregular in shape and considerably thickened. In the view shown in Fig. 11, the body rods on the right side of the figure appear as though they were fused together but apon examination of this region in different positions it seemed that there was an overlapping and not a fusion of the body rods. Associated with the absence of the aboral branches and the abbreviation of the body rods there is a marked thickening of these rods and the formation of compensatory processes at $x$ and at $x^{1}$. Such compensatory growths were present in non-fused skeletons where suppression of parts had likewise occurred, so that their formation in Fig. 11, is probably not due to the fusion of the skeleton per se. The fusion of the skeleton then has 
not introduced in this instance at least any new or additional factor in the developmental complex.

Fig. 12, is another example of two almost equal and perfect larvae fused together at $F$. The lower one as in the previous example is foreshortened and appears small in the drawing. There are two complete and independent guts, elongated in such a manner that the hind guts are almost in contact, and differ from those of figure 11, where the two guts are fused together. Both skeletons are complete and perfect with these exceptions, 1) the aboral branches of the upper larva have been suppressed as in the preceeding example, 2) there are compensatory growths at $s^{1}$ and $s^{2}$ like those found in any fusion where some skeletal structures have been suppressed, 3) in the lower larva the body rods cross each other, in a very atypic manner yet the structures are perfectly normal.

\section{b. Unequal Larvae.}

In the next group of fusions one larva is complete and perfect while the other is modified in various ways.

Fig. 13 is an example of the fusion of a perfect larva, the upper one, with a dwarfed larvae, fused together at $F$. This dwarfed larva contains all the structures which characterize the normal larva though the parts are all diminutive, and the dwarfing has effected the parts unequally. The arm rods for example are relatively, as well as absolutely, shorter than the body rods, etc. The only evidence of compensatory growth is seen in the elongated and modified architecture of the body rods and the aboral branches of the upper or dominant larva.

Fig. 14 is a good example of a fused pair in which one of the larvae is normal while the other is not dwarfed as in the preceeding instance but irregular, and this irregularity is limited to the oral end of but one side of the skeleton. The oral arm rods are not merely abbreviated but decidedly malformed. The irregular part it should be noted is confined to that part of the skeleton which is nearest the point of fusion, which suggests that the fusing region is a center of disturbance which interferes with the normal deposition of the mesenchyme cells. The usual compensatory growth is seen at $s, s^{1}$, ete.

1. One Normal and One Incomplete Larva.

Fig. 15 is an example of two fused skeletons of equal size one of which is perfect the other incomplete. The entire oral half of 
one side of the larva has been suppressed, all other parts are typical and perfect.

Fig. 16 is an interesting union of two larvae in which the apper one is quite complete, the lower one very incomplete and irregular. The lower larva has the entire lateral half of the body missing. The other lateral half of the skeleton contains all the typical parts, including even the aboral branches, but these parts show the effect of considerable disturbance. The body rod for example is sharply bent and united to the other larva at the apex of this bent rod. The single anal arm rod which is much thickened throughout has a number of accessory processes, and the single oral arm rod has also an accessory rod. This compensatory growth is here also associated with suppression in other parts, and the extent of compensatory growth is roughly. commensurate with the degree of suppression in other parts of the same or adjoining body. If there is any doubt that we are here dealing with a second larva, the presence of the complete second gut settles the matter definitely.

In Fig. 17, the upper larva is complete the lower one incomplete due to the loss of the oral balf of the skeleton, and in this respect differs from Fig. 16, in which the lateral half of the suppressed skeleton was missing. The anal region of the lower larva is essentially perfect. It contains two characteristic anal arm rods, one dorso-ventral connective, two body rods and one aboral branch, foreshortened in the drawing. Within the body region and extending from the one dorso-ventral connective is a large mass of compensatory skeletal material, $s$, extending irregularly into the body and whose parts can not be homologized with the structurea of control larvae. It should be noted that there is but one normal gut which indicates either a suppression of one gut or a complete and perfect fusion of two guts.

In Fig. 18 also, the entire oral half of the skeleton is missing in one larva, while the other is quite perfect. The anal half of the skeleton of the first larva consists of two characteristic and perfect anal arm rods and a large irregular mass of skeletal material attached to all four body rods so that it is difficult to determine whether the mass is an outgrowth of two or more of the four body rods. It is possible that the rods at $x$ represent the irregular oral arm rods, though I am inclined to believe that this is not the case. In this fusion also there is but one gut of normal size.

Fig. 19 is a splendid illustration of the complete and normal 
development of one larva and the incomplete development of the other. Like Fig. 17 and 18, only the anal half of the skeleton was formed, consisting of two characteristic and well shaped anal arm rods. Their bases which are probably the body rods, have fused with the body rods of the other larva and in the fused region the mesenchyme cells have formed a large irregular mass. Near the skeleton forming centers of the other larva there are other compensatory enlargements one at $x^{1}$ another at $x^{2}$ and $x^{3}$. There is but one gut, with the mid gut much enlarged suggesting the incomplete fusion of two guts.

Fig. 20 is interesting for several reasons, firstly, one larva is extremely small while the other is either normal or even larger than the norm, secondly, this diminutive larva is incomplete and irregular while the other larva is normal or nearly so, thirdly, compensatery growths are found in both larvae. The skeleton of the suppressed larra has two short anal arms which unite aborally into a single irregular and thick body rod ending in a single irregular aboral branch. There is no trace of the oral half of the body. The compensatory growths in the suppressed larva are situated at $s$ and $s^{1}$. There is also an accessory growth in the dominant larva namely the irregular thickening of the body rod at $x^{3}$ and the supernumerary rod at $s$. There is here also but one gut of normal size.

In Fig. 21, the suppressed larva is even more incomplete than in any of the preceeding examples. At first glance there appears to be but one larva with a superuumerary arm. On closer examination it is seen that there are two larvae. In the first place there are two independent guts, in the second place the position, connections and architecture of the three anal arms makes it practically certain that the one marked $\mathbf{v}$. a. is not a supernumerary arm but an independent arm the sole skeletal, remains of the second larva.

There are two thin slightly curved rods extending from the anal arm aborally at $x$ and two others from the aboral branch at $x$ that suggest the disintegration of skeletal parts as found in Toxopneustes. The rods at $x$ and $x^{1}$ probably represent the almost disintegrated ventral body rod.

\section{One Normal and One Extremely Atypic Larva.}

So far reference has been made only to such fusions in which the parts of the suppressed larva whether incomplete, irregular or 
dwarfed, could readily be identified or homologized with the corresponding parts of control larvae. In the following examples the skeleton of the suppressed larva has been so completely modified that none or very few of the parts can be so homologized.

In Fig. 22 for example the suppressed larva has neither the anal nor the oral arms. The skeleton consists merely of two rods probably the two body rods. The lower one which is almost normal is straight and has the branching aboral part. The upper one fused to the body rod of the other larva is very irregular. The compensatory growth has not merely modified the shape of this body rod but of the adjoining body rod and the dorso-ventral connective of the dominant larra seen at $x$. It is possible that $I$ have misinterpreted the boundary between the left and the right skeletons. For example the part at $x$ may be the aboral branch of the upper body rod of the suppressed larva and that this aboral branch is fused to the hypertrophied body rod of the left larva shown in the drawing in dotted lines. It might be noted that the gut in the suppressed larva is diminutive and incomplete and not connected to the other gut.

In Fig. 23, there is but one normal rod in the atypic larva, namely the oral arm rod. The other skeletal parts are probably the modified body rods which are very thickened and fenestrated. In this fusion also, the region where the skeleton centers of each larva come together is the region where the greatest disturbance in the deposition of the skeletal material has taken place, with the consequent atypic development of both body rods of the suppressed larva. The compensatory growth is seen in the thickened body rods of the suppressed larva and in the spinous dorso-ventral connective on the left side of the dominant larva. The guts have also fused in such a manner that there is a common mouth and foregut but separate hind gits.

In Fig. 24, the suppressed larva is still more incomplete and irregular, and might readily be overlooked or mistaken for a supernumerary structure. The presence of a small though clearly differentiated gut establishes beyond question that there are two larvae of which this small fragment is the only skeletal remains. This fragment extends directly from the enlarged body rod of the dominant larva and from it there are several thin branches, that can not be homologized with the parts of the normal larva. This specimen is interesting also because the other body rod of the dominant larva which is neither in contact nor fused with the skeleton of the 
suppressed larva is considerably modified in shape especially the conspicuous club shaped branch. That we are here not concerned with an abnormal developmental process is evidenced by the perfectly normal development of the other parts such as arms guts etc. Much more significant are the thin rods at $s, s^{1}, s^{3}$, ete. which when studied in connection with similar rods in Fig. 21, and the serial stages shown in another publication (4) strongly indicate that a disintegration process has taken place which has partially destroyed the more complete skeleton.

Fig. 25 differs from Fig. 24, in the fact that there is no evidence of a reciprocal influence. The dominant larva is perfect the suppressed one is dwarfed, very incomplete and extremely irregular. Here, there is but one gut whose mid gut is so enlarged that it extends into the suppressed larva. With the absence of the second gut and the further decrease of the right skeleton it is but a small step to the fusion shown in Fig. 26 and 27.

In both these fusions only a single larva is apparent. More detailed examination showed evidences of compensatory growth and of modifications that were never found in single larvae, but common in fused larvae and which are the sole indications of the second larva. Fig. 26 closely resembles a single larva. Both the enlargement of the two skeleton centers, and the two dorso-ventral connectives, and one of the body rods, on the left side of the figure, and the thickenings of the right oral arm rods resemble so closely the accessory growths in fused larvae and have no parallel in single larvae, that the conclusion seems inevitable that these changes represent the result of an almost complete fusion of two skeletons. This conclusion is reinforced by the presence of the fenestrated thick bar at $x$ connecting the two anal arms and which resembles an anal arm rod.

I cannot demonstrate that Fig. 27 is a fusion of two larvae though all indications point to this conclusion. There is clearly but a single gut and a single skeleton, but this skeleton bas all the indications of a fusion. There is considerable compensatory growth not unlike that found in fused larvae. One of the oral arms has a supernumerary rod, both oral arms are slightly enlarged at their bases, and the bases of the anal arm rods are considerably thickened. The body rods as well as the aboral branches are also exceedingly thick and fenestrated and somewhat bent out of shape. 


\section{c. Both Larvae Modified.}

So far I have considered only those instances in which one larva was perfect or nearly so, while the other was incomplete dwarfed or otherwise atypic. Reference will now be made to fusions in which both members are modified in various ways.

Fig. 28 is a good example of a fused pair in which the skeleton of each larva appears normal except for the total absence of one body rod from each larva. It is not improbable that the two short rods at $x$ are the disintegrated remains of one or both of these body rods. There is some evidence of compensatory growth seen in the elongated bar at $x^{1}$ in the elongated and thickened anal connectives etc. The two guts have also fused in such a manner that the mid and hind guts are common to both.

In Fig. 29 both larvae are incomplete but incomplete in different degrees. The left has but one oral arm though it contains two oral arm rods one of which is very diminutive. The right larva has neither oral arms nor dorso-ventral connectives. Evidence of compensatory growths are confined to the thickening of the dorso-ventral connective of the left larva at $x$ and $x^{1}$ and in the spinous process at $x^{2}$. Fig. 29 and 28 may serve as examples of the atypic development of both larvae due to the suppression of the skeletal parts in both. In other instances the atypic development may be due not only to this suppression but to a great accumulation of mesenchyme in atypic positions.

For example in Fig. 30, there are two larvae, each with four characteristic arm rods. The right larva is seen in side view and only half of the skeleton is drawn. Certain minor changes are seen in the oral arms of the left larva which are rather short; but a much more profound change is seen in the absence of the left body rods and their aboral branches and the union of the anal arms of the left larva with those of the right larva. Where they unite there is an unusually enlarged irregular fenestrated mass that is probably the enlarged body rod and aboral branches of the right larva. The irregularity of the skeletons then is limited to the body region only, and is due in all likelihood to the migration of the mesenchyme cells to the body rod and aboral branches of the other larva forming there the irregular compensatory growth just mentioned.

In Fig. 31 the suppression of the skeleton is much greater and the compensatory growth is correspondingly greater. The four arms 
of the dominant larva contain the characteristic normal arm rods. The suppressed larva is represented by a single anal arm containing one normal anal rod. The rest of the skeleton of the suppressed larva seems to have been added to the skeleton of the dominant larva or that part of it situated within the common body, so that their body rods and aboral branches are surrounded by an immense fenestrated mass of skeleton material which makes both larval skeletons secondarily very irregular. These two larva have but one gut whose mid gut is very much enlarged.

In Fig. 32 parts of the skeleton in both larva have been suppressed and the compensatory growth occurred also in both larvae, with the result that the pair is extremely irregular. There are four arms which from their position and from the character of the rods are undoubtedly all anal arms. There is no trace of any of the oral arms. Arms 1 and 2 probably belong to one skeleton and arms 3 and 4 belong to the other. In the region of fusion the mass of fenestrated calcareous material connects the four body rods together and makes more irregular the already irregular larvae.

In Fig. 33 also both larvae are incomplete i. e. the oral half of each is missing but there is much less compensatory skeletal growth than in the preceeding example. It is probable that anal arms 1 and 2 belong to one larva and anal arm 3 to another. The club like bar at $s$ probably represents a modified oral arm, $s^{2}$ a modified anal connective. It will be observed that anal arm 3 is really composed of two anal arm rods fused together. The compensatory growths are confined largely to the aboral regions.

It might be urged that in Fig. 33 we are dealing with a very atypic development in which the results are due not to any reciprocal influence of the two fused larvae upon one another, but to the originally weak or injured eggs. Fig. 34 is of interest in this connection because of the almost perfect development of the anal half of one larva and the anal quarter of the other, yet each of the parts differentiated is perfect, rendering the assumption of an unfavorable environment or of an injured egg beside the mark.

Fig. 35 and 36 which are two views of the same fusion, are inserted even though it is difficult to state with definiteness whether it represents a single or a double larva. In any event there are some very interesting regulations which deserve attention. There are three anal arm rods and three oral arm rods. From the anal view Fig. 36 it is seen that the two anal arm rods on the left are united 
in the middle, the right one is joined to the single anal arm on the right side of the drawing, while the other of the pair ends blindly. The body rod and the aboral branch on the right side are normal. On the left the body rod instead of connecting with the anal arm is joined directly as shown in Fig. 35 to the oral arm rod. On the other side of the body, the body rod bends orally into the enlarged dorso-ventral connective, and branches into two oral arm rods instead. There is but one normal gat. It is altogether probable that this fusion was brought about by the suppression of some parts and the disintegration of other parts in each larva.

Fig. 37 is clearly not a fusion of two skeletons. It is inserted here because it shows some very interesting regulations. This is an extreme illustration of the unequal development of two larvae. The upper one is fully and perfectly formed the lower one is very undeveloped. It contains a tripartite gut and two embryonic triradiate spicules one of which is very much branched. From the left body rod of the dominant larva a very branched mass of skeletal material extends towards these spicules but does not unite with them. All the parts of the dominant skeleton are perfect. The mass at $x$ could be produced by the migration of cells either from the lower larva towards the left body rod of the dominant larva, or in the reverse direction from the left body rod into the lower larva. All observations argue against the latter view. It is altogether probable that the mesenchyme cells that might have given rise to the skeleton of the lower larva have migrated or been drawn to the left body rod where their skeletal material was deposited.

\section{Discussion.}

It is perhaps unnecessary to state that the examples of fused larvae described in this paper are but a few, taken almost at random from a very much larger number. They are I believe representative as to the types of fusions and as to their relative frequency.

These fused larvae show the same types of fusion and the same regulative phenomena that obtain in Toxopneustes. In both echinoderms the two fused larvae, and their contained skeletons may be equal and normal, or unequal and normal, or unequal and abnormal. This inequality in development was not due to any difference in age but rather to the direct influence of one larva the more vigorous or the more rapidly developing one upon the less vigorous or less rap- 
idly developing larva. As a result of the influence of the dominant larva the »suppressed " one may show any of the following changes:

1) all the skeletal parts of one larva may be abbreviated giving rise to a dwarfed but otherwise perfect larva,

2) one or more parts of the skeleton may be abbreviated or entirely missing though all other parts of the skeleton or larva may be perfect,

3) one or more parts of the skeleton may be malformed though the rest of the skeleton is perfect.

Some of these changes may be found in control cultures but not in sufficient numbers to account for their presence in nearly every fusion. Furthermore the changes that superficially resembled the controls differed from them in detail, and lastly there were types that were never found in control cultures. These facts suggest that they arose as a result of other factors than those that obtain in control or single larvae. And it is highly probable that they are a consequence of the fusion process per se.

There were other changes in the skeleton found in both echinoderms that are of special interest. These changes are associated with the behavior of the mesenchyme cells. It is known that the skeletons arise in two lateral centers where the mesenchyme cells collect and form the triradiate spicules, and later the rest of the delicate skeleton. When the skeleton centers of two larvae are brought close together by the fusion of the larvae in certain positions, the normal migration and distribution of the skeletal material is usually disturbed so that the mesenchyme cells are deposited either in other parts of the same larva or in the adjoining larva, near a skeleton center.

If all the mesenchyme cells are withdrawn from one of the centers, only the lateral half of the skeleton is formed, and there were many instances of this kind of skeleton. If the mesenchyme cells from one center are only partially scattered, the oral or aboral half of one side would be missing. There were a number of examples of this kind of skeleton. When some of the mesenchyme cells are withdrawn from both centers, either the oral region is incomplete or a dwarfed skeleton is produced. In no case were all the mesenchyme cells from both centers withdrawn, with the consequent total loss of the skeleton. Possibly this may take place when fusion occurs in the egg stage, and thus give rise to a true sgiant* larva as described by Driesch. 
The larva which is incomplete might be termed the »suppressed * larva though it is evident that this term does not give a true idea of what has actually happened, because the original suppression of part of the skeleton may subsequently be modified by the further reduction of skeletal parts in a very different manner, until all but one or two of the twelve characteristic parts of the skeleton are missing

As has been pointed out the mesenchyme cells are attracted towards one or another of the skeleton centers where they deposit their skeleton material and build compensatory or accessory parts. The amount of this accessory material corresponds most strikingly with the loss of skeletal parts in other regions, and gives further support to the view that a displacement rather than a suppression per se took place. But it should be noted that the migration of the mesenchyme, or the difference in the position of the new skeletal material, has interfered with normal deposition, for in every instance of fusing larvae such compensatory growths bears no resemblance to the normal structures of the skeleton.

Besides the suppression of some parts of the skeleton, and the formation of accessory parts, there is a third change, just referred to, that is found ordinarily in but one of the fused larvae. This change involves a malformation of one or more of the skeletal parts and in extreme cases of the entire skeleton. Such malformations may vary slightly from the norm, or may be so complete that all homology with corresponding parts in the control larvae are exceedingly difficult or impossible. The character of these malformations suggest that the same or similar forces that attracted the mesenchyme cells to other regions, have in these instances only partially withdrawn or only partially shifted the position of the mesenchyme cells from their original center, so that the resulting structures are also shunted or twisted out of shape. It seems very probably that the proximity of a skeleton center of another larva made for a more or less incomplete or irregular skeleton. One cannot help noting the numerons instances when the irregularity was increased when the skeletons were fused as though the disturbance travelled along the skeleton to the parts then forming, as seen in Figs. 12, 14, 22, 23 and 24 ete.

In all these matters Arbacia and Toxopneustes are in complete agreement. In one respect however to the Arbacia differ completely from Toxopneustes, namely that the Arbacia skeletons tended to fuse together very readily, while in Toxopneustes the skeletons were never 
observed to fuse. But this fusion in the Arbacia did not involve the production of any new types of fused larvae, nor was there any evidence of a new factor in such fusing skeletons.

It is known that when two blastulae are in contact they tend to fuse by the disappearance of their connecting wall, and that they tend to approximate the shape of a single blastula, somewhat enlarged. Similarly when two gastrulae are fused so that their guts are in contact, these tend to fuse by the disappearance of the connecting wall and subsequently tend to be remoulded into a single gut often of a single size. When not in contact each gut develops independently and completely. In the fused larvae shown in this paper, the two guts were equally and perfectly developed and independent in three instances, independent and unequal in six instances, fused yet showing the dual character of the two guts in 3 instances, fused and showing no trace of the dual composition in 14 instances. In a few of these the single gut was larger than the norm, but in most, there was no recognizable difference. Whether in these instances two guts had fused completely into one or whether one of the guts had been completely suppressed cannot be determined from the study of the larval stage. If these examples be taken as representative, and if earlier studies on Arbacia be taken into account it will be evident that there is a decided tendency to suppress one of the guts or to unequal development, and the subsequent fusion and form regulation so far as the guts are concerned.

The skeletons of fusing larvae differ from the ectoderm and the entoderm, in the fact that regulative changes in the skeletons do occur even when they are not in contact, nor fused together, though the fusion of the skeletons makes for a more rapid and more complete series of regulative changes. This is shown by grouping the fused larvae as follows: 1) whether the skeletons were or were not fused, 2) whether the skeletal centers were or were not close together, 3) whether the skeletons were or were not normal. It was found that when the skeletons were not fused together many developed normally, that when the skeletons were fused together one or both were irregular, that there were decidedly more irregularities when the skeleton centers wete close together than when they were apart. In other words the normal developmental process was considerably interfered with either by the skeletal centers directly or indirectly across the skeletal mass to the developing end, or by both these factors, with corresponding irregularities in the skeleton formation. 
The situation is rendered far more complicated by the fact that definite disintegrative processes occur in the fusions of Arbacia and Toxopneustes. I have found no evidence of disintegration in control single larvae. In the fused larvae of Toxopneustes the evidence was very clear that disintegration of the skeleton in the suppressed larva took place, and a gradient series of stages were obtained showing the increasing disintegration of the skeleton, until all but one of the 12 characteristic parts were lost. In Arbacia the evidence is much less clear due to the nature of the accessory growth. In Toxopneustes this growth was very inconsiderable and was deposited in thin bars single or slightly branched. In Arbacia the accessory growth was very great and laid down in large thick fenestrated masses. The disintegration of the bars in Toxopneustes was readily perceived due to the shortening and thinning of the bars. In Arbacia it was exceedingly difficult to observe small disintegrations. It is altogether probable that in the few instances where there was little or no accessory growth the result was due not to a lack of this accessory growth but to a more complete disintegration of this growth.

The significance of these changes lies not so much in the fact that disintegration of formed parts took place, but that there appears to be a selective disintegration by which accessory and even normal parts in the suppressed larva disappeared, so that the two larvae tended to be remoulded more or less completely into a single larva. This phenomenon of form regulation effected as we have seen all three germ layers, namely the body wall the gat and the skeleton.

The facts so far indicate that definite types of changes occur usually in the suppressed larva. Yet there are unmistakeable evidences of a reciprocal influence not merely of the dominant larva upon the suppressed one, but also in the reverse direction. In earlier studies subsequently corroborated by DE HAAN, and those of DRIESCH it was shown that under certain cireumstances only one gut was formed in a fused pair of blastalae, the other is completely suppressed. In several of the larvae described in this paper it was shown that the gut may be formed in but one of the two larvae namely in the dominant larva, and that this gut may be shifted in its position or enlarged or changed in shape, so that part may occupy both larvae. It is altogether improbable that these changes indicate a partial fusion of two guts. A reciprocal effect was also observed in the different skeletons. The mesenchyme cells were commonly transferred from a suppressed larva into the dominant one, 
but sometimes the transfer was in the reverse direction. Or the position or shape of one or both skeletons was so modified when the skeleton centers of two larvae were brought close together during the fusion of the larvae. Or the parts of one skeleton were suppressed retarded or disintegrated leaving a vacant area, and into this area the accessory skeleton of the dominant larva grew in such a manner that this area contained a skeletal framework supplied by the adjoining skeleton. This framework did not contain the characteristic structures of the missing skeleton but they presumably effectively compensated for the loss of the missing parts.

De HAAN suggested that the irregularities in fused larvae might be due to a defect in the egg or embryo or to some adverse environmental factor. If these irregularities were due to these causes we shoulf expect that the atypic larvae would belong to the same types as those in cultures of bad eggs or cultures of good eggs placed in abnormal conditions, or at least that the ratio of irregular to normal larvae be the same in fused as well as single larvae. The facts clearly show that the types of irregularities are in the main quite different in character from those that occur in single larvae, under any conditions, and that the irregularities are limited usually to but one of the fused pair. On DE HAAN's view one must assume that all atypic eggs or embryos were by some selective process caused to fuse with normal eggs. Even when we make this assumption there is the difficulty to account for the excess number of irregularities over and beyond what is found in control larvae, and to account for the fact that in nearly every instance only one larva is so effected, and lastly that the types of irregularities are different from the controls.

When it is recalled that sea urchin eggs are highly sensitive to small changes in the surrounding medium, that one in every fused pair was nearly always norm that the irregularities were not like those found in unfarorable cultures, it follows that the specific changes in these fusions are due not to abnormal eggs nor to abnormal conditions but to the influence of one larvae upon another.

The regulative changes discussed are very complex involving suppressions retardations, migration of parts, the formation of accessory growths and the disintegration of parts. And the rate and extent of the changes varies with the nature of the fusion and more particularly with the proximity of the skeleton centers of the two larvae, for the development of the non-skeleton parts is conditioned 
by the development of the skeleton. Furthermore the body wall the gut and the skeleton vary in the rate and completeness of their fusion. The end result however of all these changes seems to be an approximation toward the specific shape and structure of a single larva.

It would be exceedingly interesting to make similar studies upon fusions of two different species of eggs, where the marked difference in the skeletons would help to throw further light upon the nature of the regulative changes involved, and the possible production of graft hybrids.

\section{Summary.}

Large numbers of separately fertilized eggs of Arbacia were fused together by means of isotonic or bypotonic $\mathrm{NaCl}$ solutions in sea water.

Only fusions of two eggs developed into the full plutens or larval stage. When more than two eggs were fused together they invariably died before reaching this stage.

The fused larvae were kept alive for 14 days without undergoing any material change except a small reduction in size.

These fused larvae may be grouped as follows:

1) fused bodies with separate and complete skeletons and guts, several types,

2) fused bodies with separate and complete skeletons, guts fused together,

3) fused bodies, fused skeletons, guts fused or not fused, several types,

4) fused bodies, fused skeletons one gut, two types.

The fused larvae may be equal, complete and perfect, both in Arbacia and in Toxopneustes. More frequently only one larva is normal while the other is modified in various ways. This modified larva may be smaller than its partner, or lacking in one or more of its parts, it may be malformed in one or more of its parts or accessory growths may still further render it atypic.

Some of these modifications in this larva superficially resemble similar irregularities in control larvae. In detail they differ markedly from these types of irregularities while other types are found exclusively in fused larvae only, making it highly probable that they are associated with the fusion per se. 
Another kind ot change is found in these modified or suppressed larvae namely a disintegration of parts previously differentiated. As a result of these disintegrative processes the already dwarfed and incomplete larva is rendered still more incomplete and smaller.

These regulative processes tended to form equilibrium, so that in extreme cases the dual larva very closely approximated a single one, with one or more skeletal bars as the sole remains of the second larva.

Considerable migration of mesenchyme cells occurred, particularly when the skeletons fused. The mesenchyme cells were either completely transferred from the skeletal centers, with the consequent loss of the lateral half of the skeleton, or partially withdrawn from both centers with the loss of the oral or aboral half of the skeleton, ete. Such mesenchyme cells were attracted to another skeleton center either in the same or in the adjoining larva, and there gave rise to accessory growths whose size bore a striking relation to the loss of skeletal parts in other regions. These accessory growths in Toxopneustes were rod like, while in Arbacia they were irregular thick fenestrated masses which disintegrated very much more slowly and less completely than in the Arbacia.

The dominant larva in most instances effected the suppressed larva; in other instances there was unmistakeable evidence of a reciprocal influence of the suppressed upon the dominant larra.

The parallelism in Arbacia and Toxopneustes is almost complete except for the fact that the fusion of the skeletons occurred only in Arbaciu.

\section{Zusammenfassung,}

Große Zahlen einzeln befruchteter Eier von Arbacia wurden miteinander mit Hilfe isotonischer und hypotonischer NaCl-Lösungen in Seewasser verschmolzen.

Nur Verschmelzungen zweier Eier entwickelten sich zum vollwertigen Pluteusoder Larvenstadium. Wurden mehr als zwei Eier miteinander verschmolzen, so starben sie unweigerlich vor Erreichung dieses Stadiums.

Die verschmolzenen Larven wurden 14 Tage lang am Leben erhalten, ohne daß sie eine materielle Veränderung erlitten, ausgenommen eine geringe Größenredaktion.

Die so verschmolzenen Larven lassen sich wie folgt gruppieren:

1) verschmolzene Leiber mit getrennten und vollständigen Skeleten und Därmen, mehrere Typen,

2) verschmolzene Leiber mit getrennten und vollständigen Skeleten, aber verschmolzenen Därmen, 
3) Leiber und Skelete verschmolzen, Därme verschmolzen oder nicht, mebrere Typen,

4) Leiber und Skelete vereinigt, nur ein Darm, zwei Typen.

Die verschmolzenen Larven können äqual, vollständig and voll ausgebildet sein, sowohl bei Arbacia wie bei Toxopneustes. Häufiger ist nur eine Larve normal, während die andere in verschiedenartiger Weise verändert ist. Diese abgeänderte Larve kann kleiner sein als ihr Partner oder auch defekt in dem einen oder andern ihrer Teile, sie kann in einem oder mehreren ihrer Teile mißbildet sein oder durch accessorische Wachstamsvorgänge zur atypischen werden.

Einige von den Abänderungen der betreffenden Larven ähneln oberflächlich gewissen UnregelmäBigkeiten der Kontrollarven. Im Detail zeigen sie ausgesprochene Unterschiede von diesen Unregelmäßigkeitstypen, während andere Typen allein und ansschließlich bei verschmolzenen Larven vorkommen, wodurch ihre Bedingtheit durch die Verschmelzang an sich in hohem Maße wahrscheinlich wird.

Noch eine andere Art von Veränderung findet man bei diesen abgeänderten oder unterdrückten Larven, nämlich eine Desintegration von vorher differenzierten T'eilen. Als ein Ergebnis dieses Desintegrierangsprozesses wird die bereits zwerghafte und nnvollständige Larve noch unvollständiger und kleiner.

Diese Regulierungsvorgänge strebten die Herstellung eines Gleichgewichtszustandes an, so daß in extremen Fällen die Doppellarve sich sehr eng einer einfachen annäherte, mit ein oder zwei Skeletstangen als einzigen Überbleibseln der zweiten Larve.

Erhebliche Wanderungen von Mesenchymzellen kamen vor, speziell wenn die Skelete verschmolzen. Die Mesenchymzellen wurden entweder vollständig ans den Skeletzentren weggebracht, mit der Folge des Verlustes der lateralen Skelethälfte, oder teilweise beiden Zentren entzogen mit Verlust der oralen oder aboralen Skelethälfte usw. Solche Mesenchymzellen wurden von einem andern Skeletzentrum entweder in derselben oder der angehefteten Larve angezogen und verursachten hier Wachstumsvorgänge, deren Ausdehnung eine überraschende Beziehung zu dem anderweitigen Verlust an Skeletteilen aufwies. Das so bei Toxopneustes accessorisch Erzeugte hatte die Gestalt von Stangen, während es bei Arbacia in Gestalt dicker, gefensterter, unregelmäßiger Massen auftrat, die sich sehr viel langsamer und unvollständiger zertrennten als bei Arbacia.

Die dominierende Larve prägte in den meisten Fällen der unterdrückten Larve ihren Stempel auf; in andern Fällen bestanden nnverkennbare Zeichen eines umgekehrten Einflusses der abhängigen Larve auf die dominierende.

Der Parallelismus zwischen Arbacia und Toxopneustes ist ein fast vollständiger, abgesehen von dem Umstande, daß die Verschmelzung der Skelete nur bei Arbacia vorkam.

(Übersetzt von W. Gebhardt.) 
604 A. J. Goldfarb, Experimentally Fused Larvae of Echinoderms etc. 2.

\section{Bibliography.}

1) Driesch, H., The Science and Philosophy of the Organism. 1907.

2) Bierens de HaAN, J. A., Über die Entwicklung heterogener Verschmelzungen bei Echiniden. Arch. f. Entw.-Mech. Bd. 36. 1913. Bd. 37. 1913.

3) Goldfarb, A. J., Studies in the Production of Grafted Embryos. Biol. Bull. Vol. 24. 1913.

4) - Experimentally fused Larvae of Echinoderms with Special Reference to their Skeletons. No. 183, Papers from the Tortugas Laboratory of the Carnegie Institution of Washington. 1914.

5) Tennent, D. H., Variations in Echinoid Plutei. Journ. of Exp. Zool. Vol. 8. 1910.

6) Driesch, H., Studien über das Regulationsvermögen der Organismen. IV. Die Verschmelzung der Individualität bei Echinidenkeimen. Arch. f. Entw.Mech. Bd. 10. 1900.

\section{List of Abbreviations}

used in the drawings.

Dominant Larva

$C$

F.G

$\theta$

H. $G$

M. G

$S$

S.C

$X$
Suppressed Larva

$\begin{array}{ll}c & \text { compensatory growth, } \\ f . g & \text { foregnt, } \\ g & \text { gat, } \\ h . g & \text { hind gut, } \\ m . g & \text { mid gut, } \\ s & \text { supernumerary rod, } \\ \text { s.c } & \text { skeleton center, } \\ x & \text { accessory growth. }\end{array}$



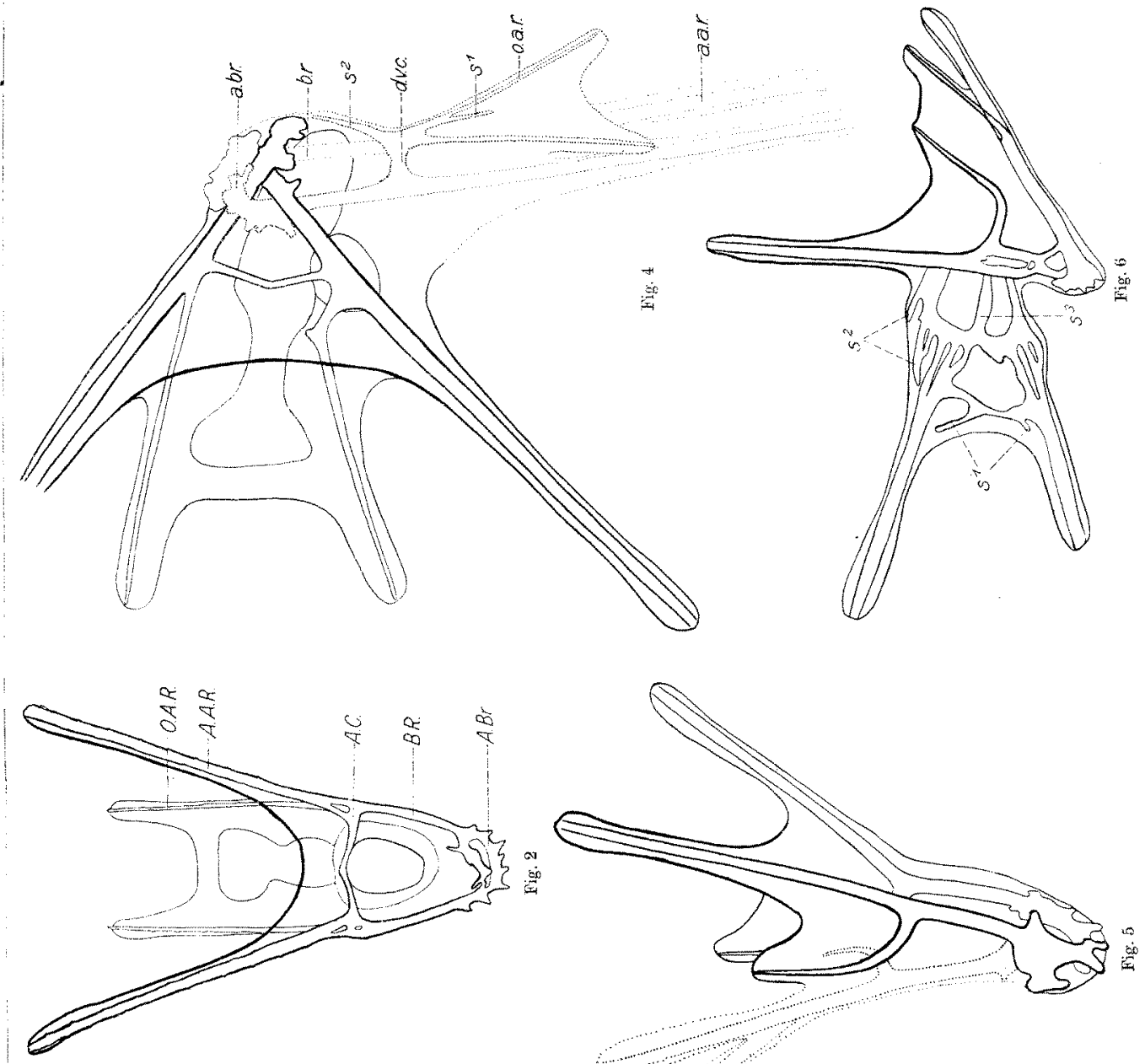

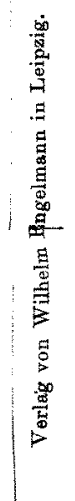

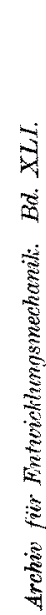
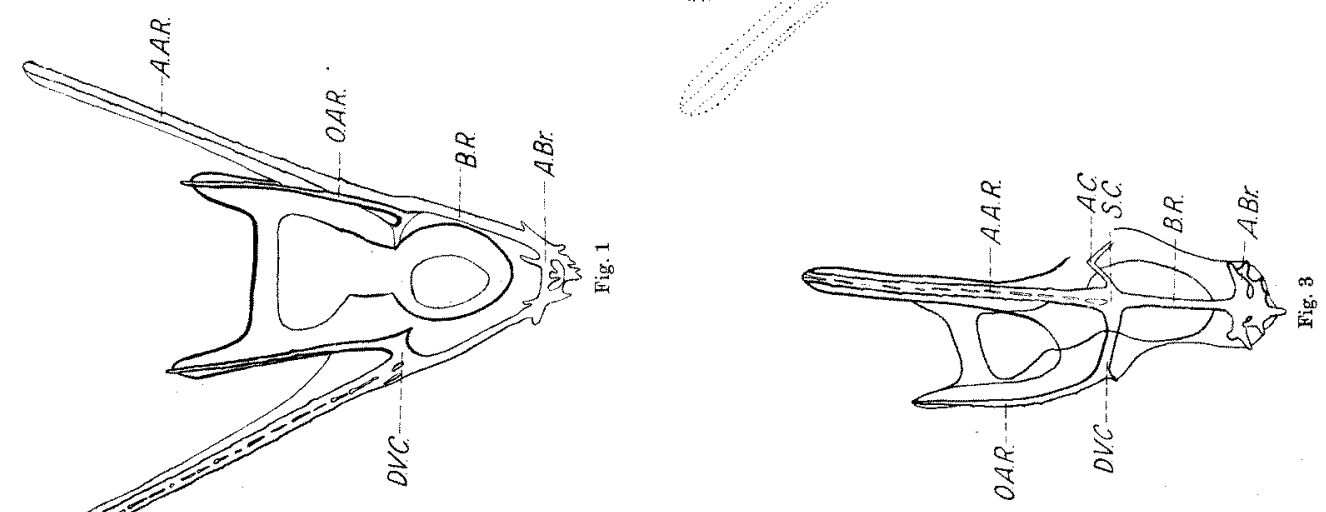


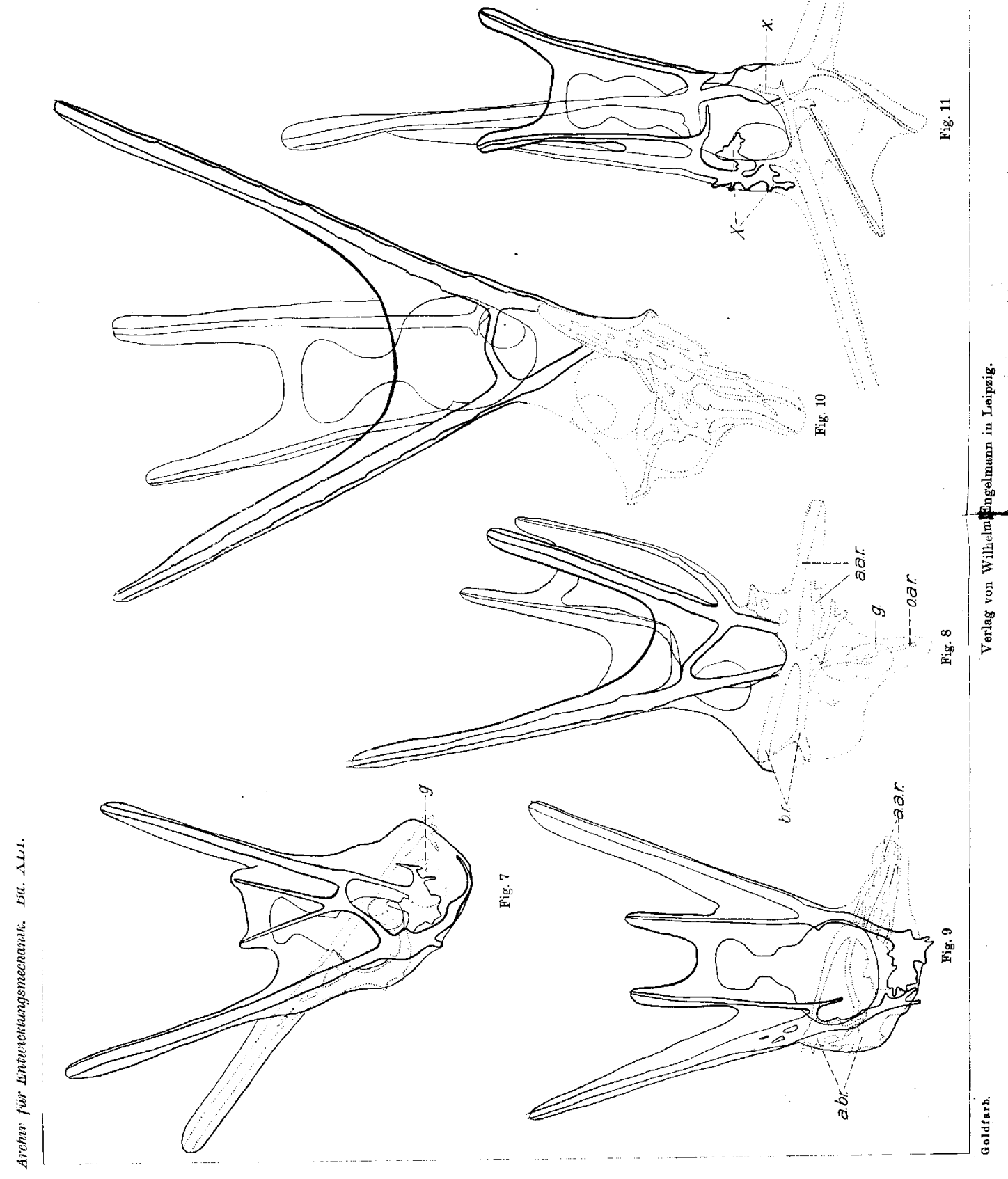



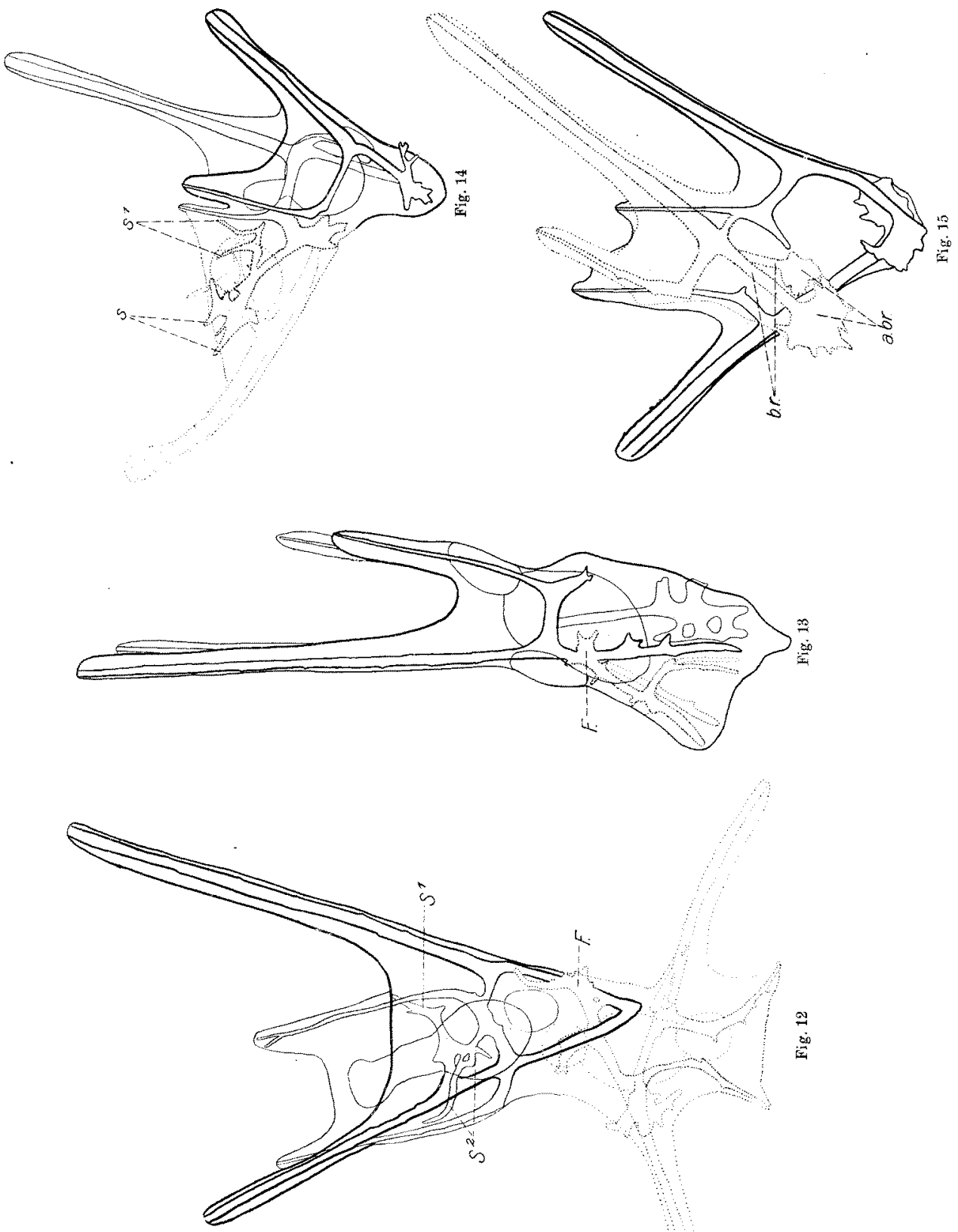

원 
$\overrightarrow{5}$
$\frac{\vec{a}}{3}$

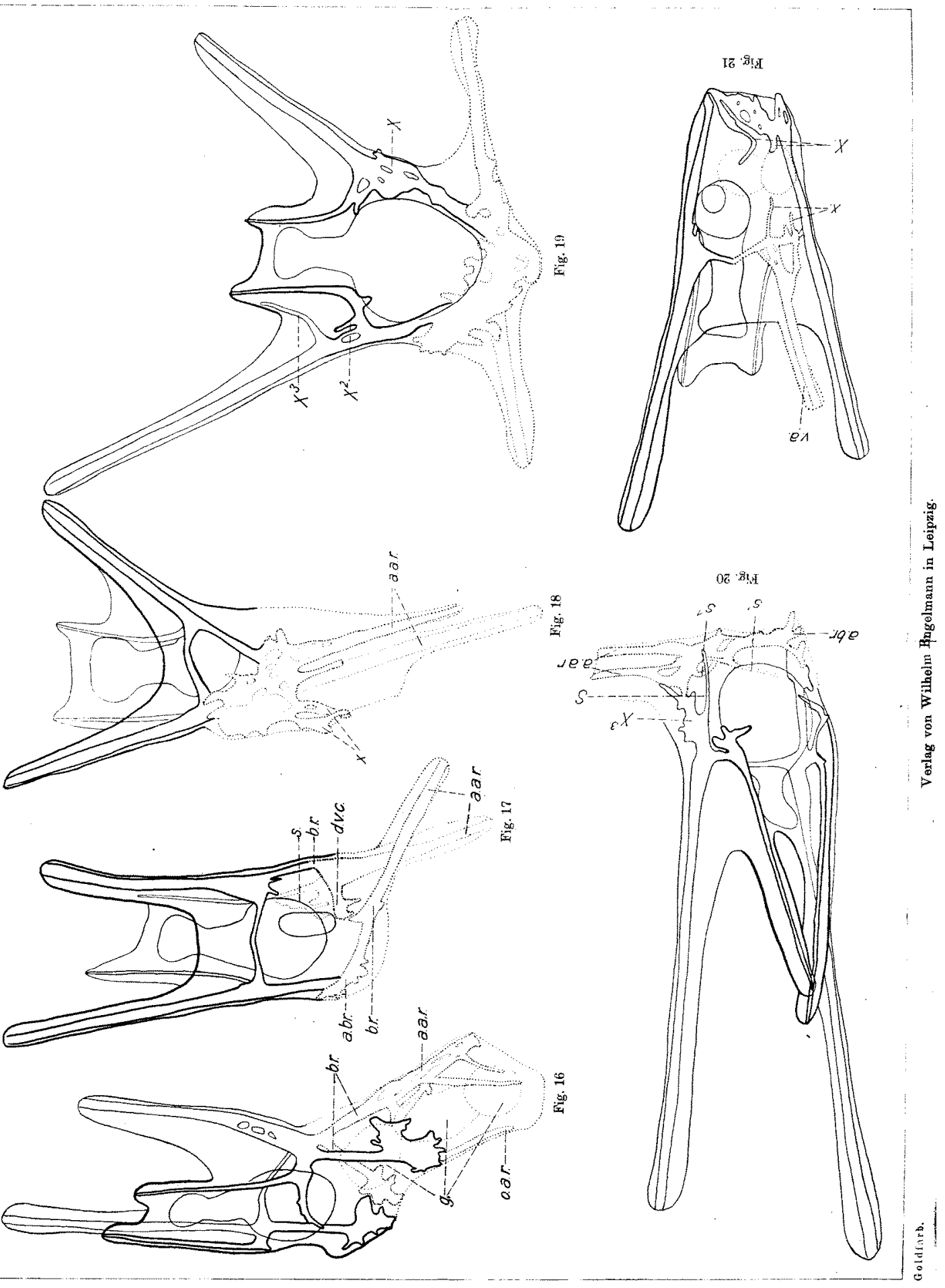



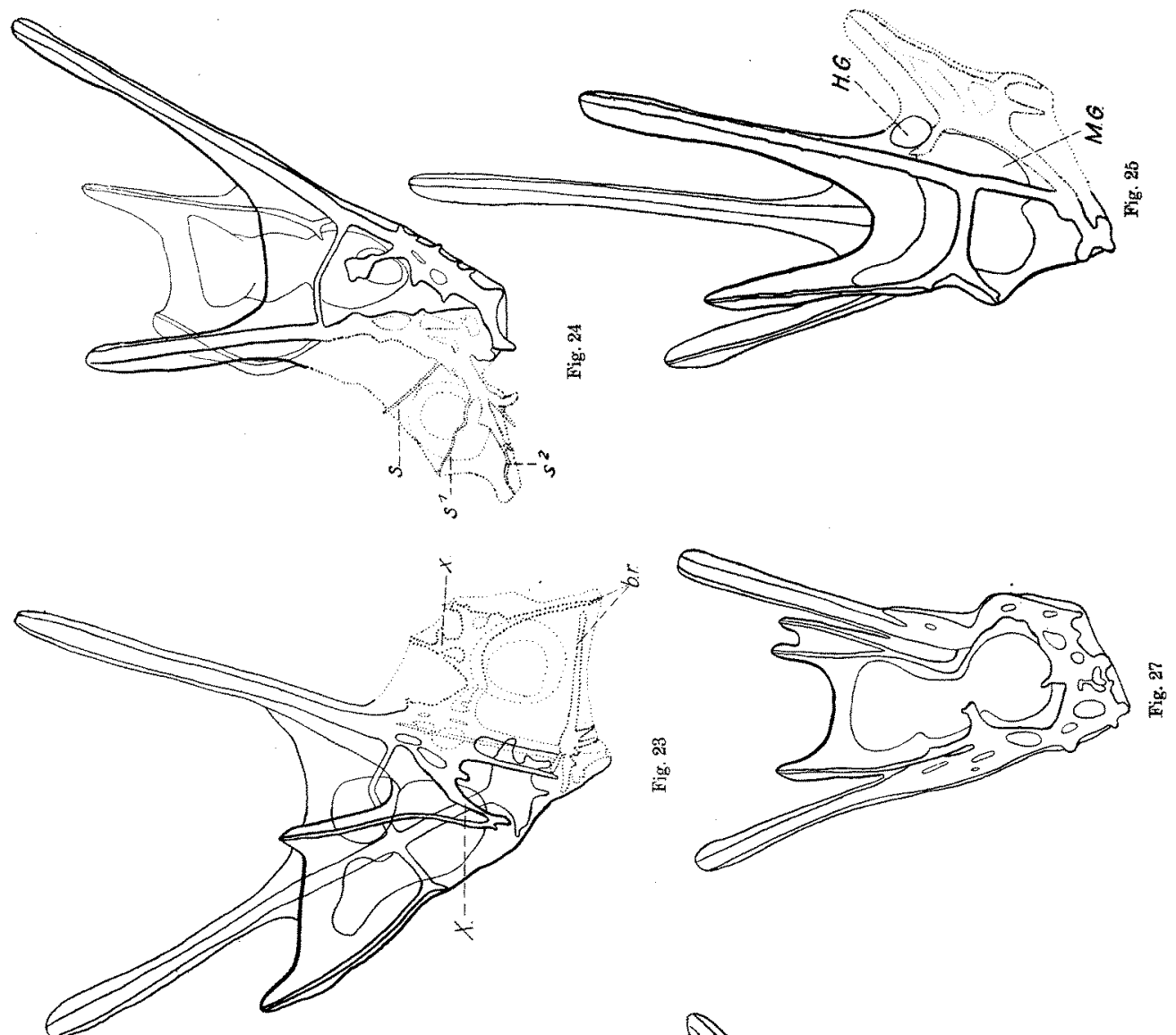

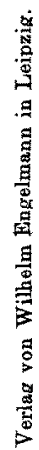

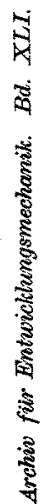
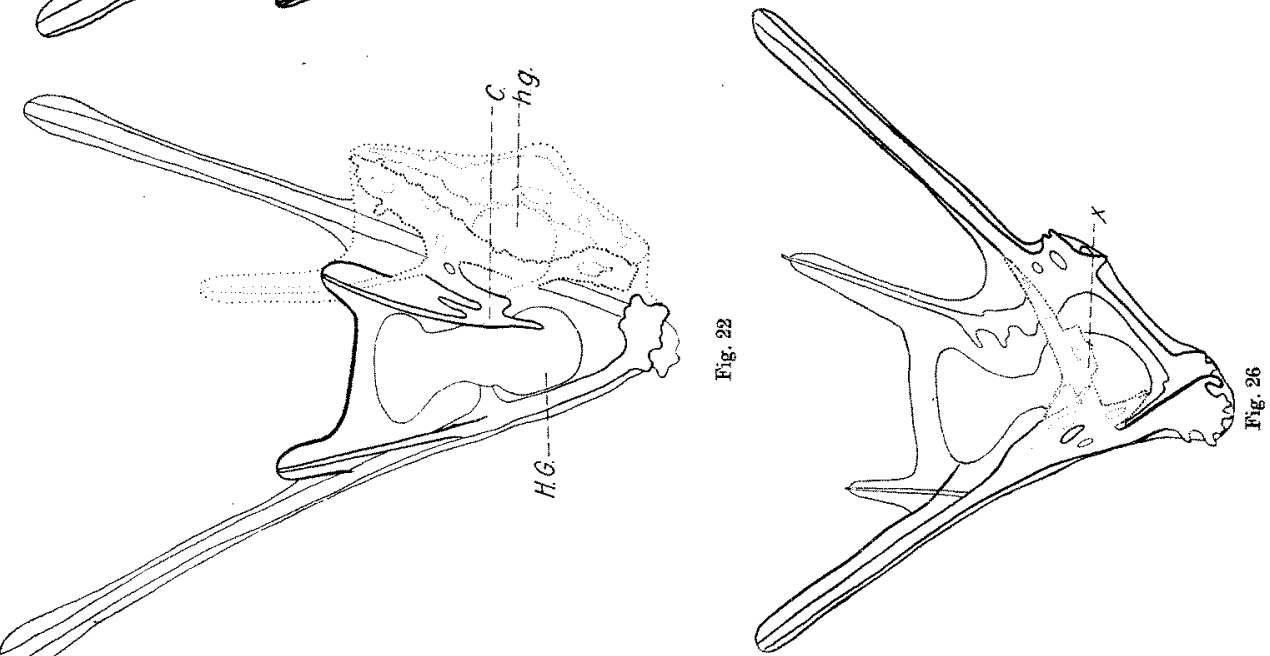

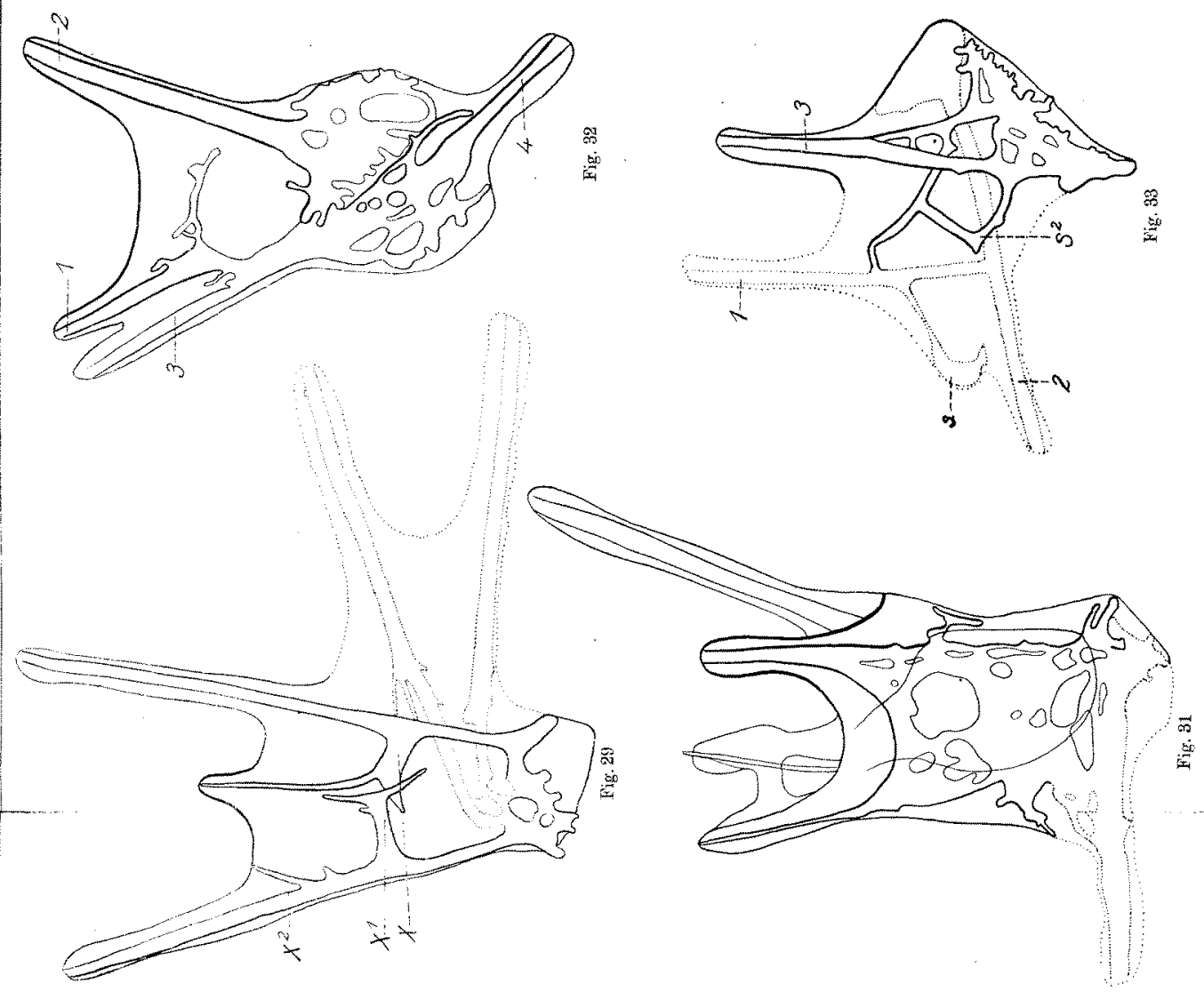

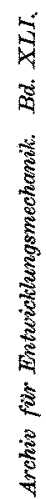
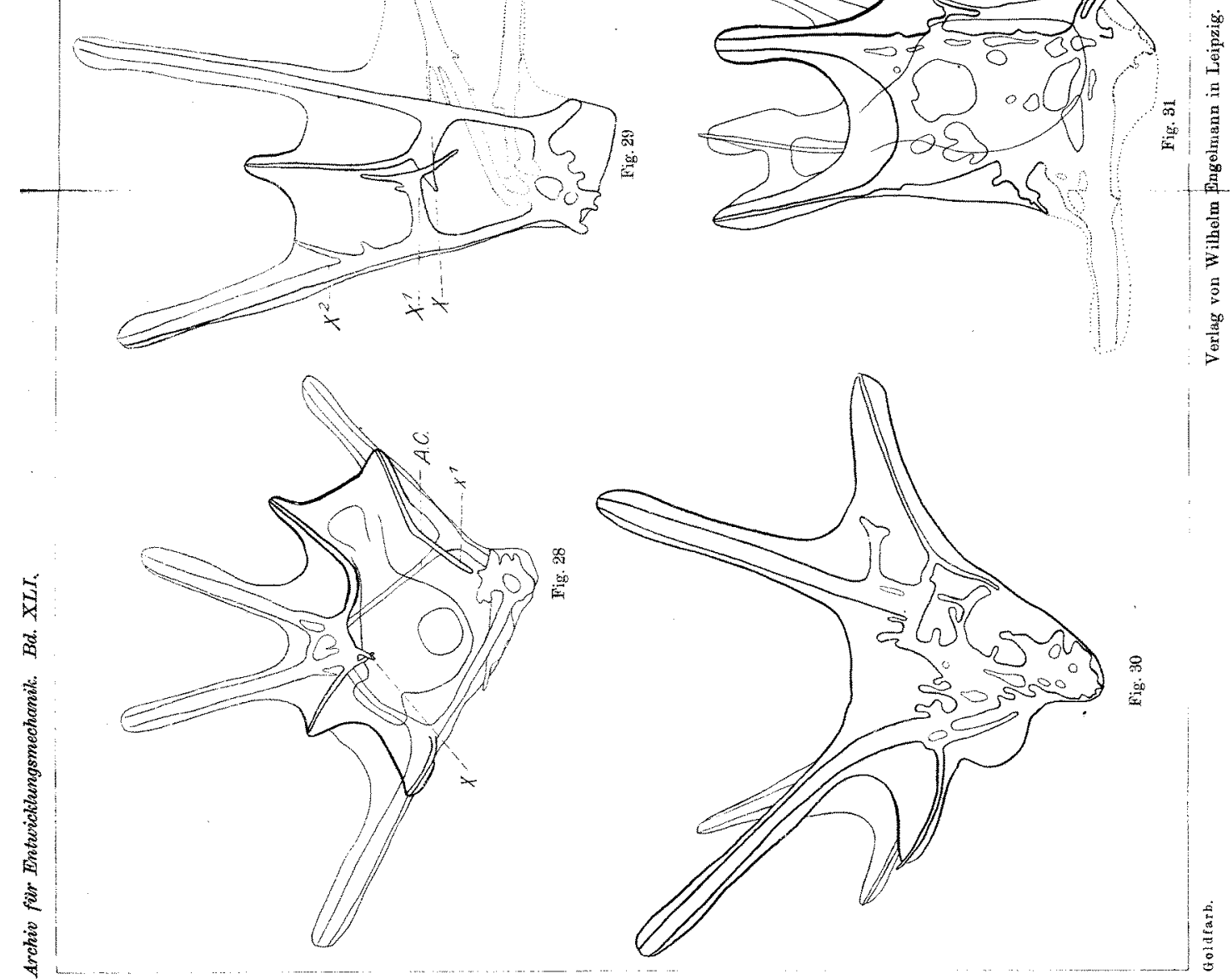


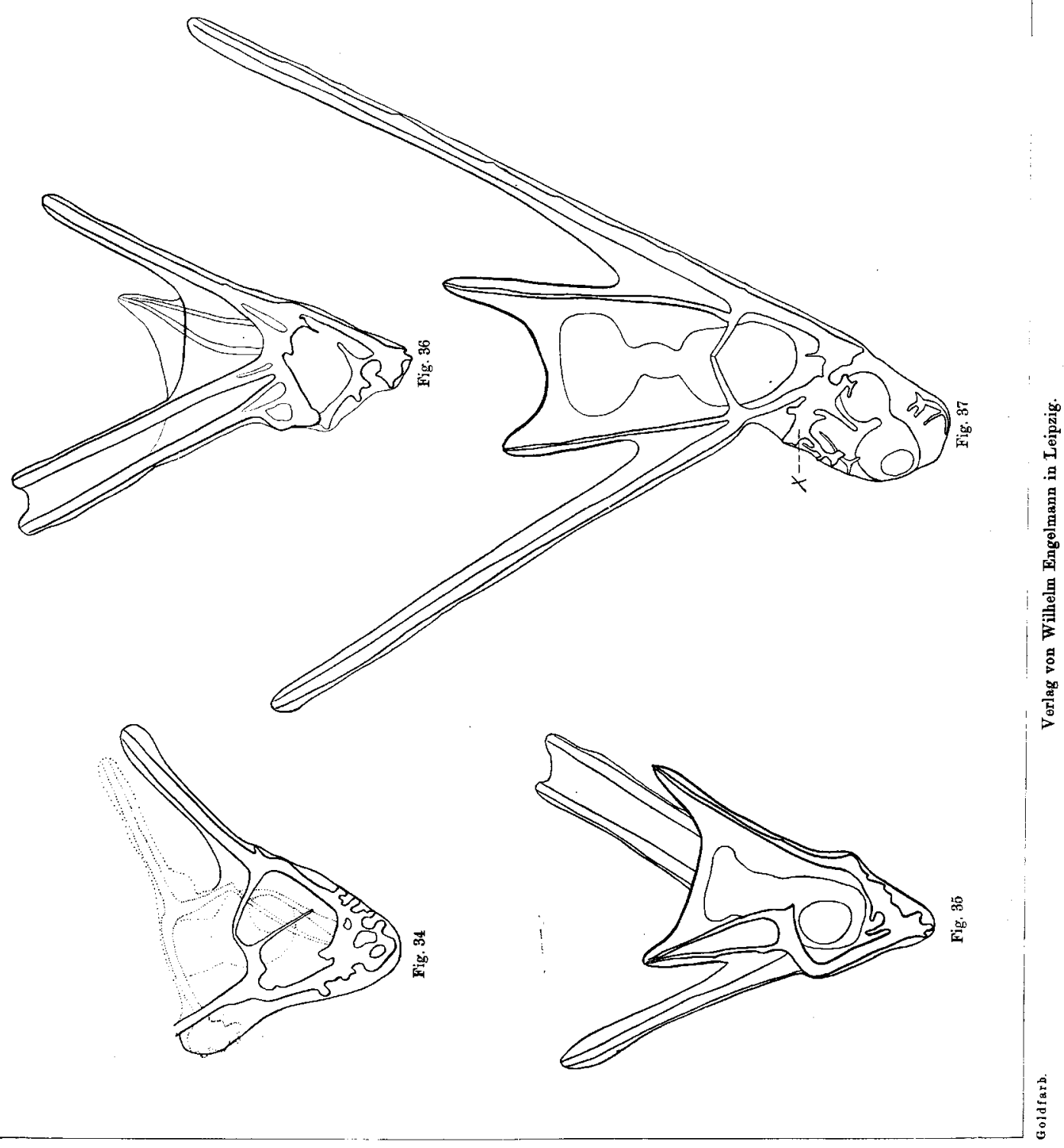

